\title{
p63 and p73, the Ancestors of p53
}

\author{
V. Dötsch ${ }^{1}$, F. Bernassola ${ }^{2}$, D. Coutandin ${ }^{1}$, E. Candi ${ }^{2}$, and G. Melino ${ }^{2,3}$ \\ ${ }^{1}$ Institute of Biophysical Chemistry, Goethe University, Frankfurt am Main, Germany \\ ${ }^{2}$ IDI-IRCCS Biochemistry Laboratory, Department of Experimental Medicine and Biochemical Sciences, \\ University of Rome "Tor Vergata", Via Montpellier 1, 00133 Rome, Italy \\ ${ }^{3}$ Medical Research Council, Toxicology Unit, Hodgkin Building, Leicester University, Lancaster Road, \\ P.O. Box 138, Leicester LE1 9HN, United Kingdom \\ Correspondence: gm89@leicester.ac.uk
}

p73 and p63 are two homologs of the tumor suppressive transcription factor p53. Given the high degree of structural similarity shared by the p53 family members, p73 and p63 can bind and activate transcription from the majority of the p53-responsive promoters. Besides overlapping functions shared with p53 (i.e., induction of apoptosis in response to cellular stress), the existence of extensive structural variability within the family determines unique roles for p63 and p73. Their crucial and specific functions in controlling development and differentiation are well exemplified by the p63 and p73 knockout mouse phenotypes. Here, we describe the contribution of p63 and p73 to human pathology with emphasis on their roles in tumorigenesis and development.

$\mathrm{p}^{\mathrm{s}}$ 63 (Yang et al. 1998) and p73 (Jost et al. 1997; Kaghad et al. 1997) are two structural and functional homologs of the tumor suppressing transcription factor $\mathrm{p} 53$. As a result of sharing similar domain architecture and sequence identity with p53, p73 and p63 can form oligomers, bind DNA, transactivate p53responsive genes, and mediate cell cycle arrest, cellular senescence, and apoptosis in response to DNA damage (Jost et al. 1997; Yang et al. 1998; De Laurenzi et al. 1998; Melino et al. 2004; Keyes et al. 2005) (See Fig. 1).

Because of splicing events occurring at the carboxy-terminal end, and to the presence of an alternative promoter located in the third intron, both p63 and p73 exist as multiple protein variants, displaying similar or antagonistic activities. The full-length isoforms (TAp63 and TAp73), containing a transactivation domain (TAD), generally behave similarly to p53 in terms of overlapping target promoters and biological functions. Among the TA variants, alternative splicing events generate proteins displaying different transactivation capacity. The usage of the alternative promoter produces amino-terminally truncated $\Delta \mathrm{N}$ isoforms, which are devoid of the TAD and therefore transcriptionally inactive. As a consequence, these

Editors: Arnold J. Levine and David P. Lane

Additional Perspectives on The p53 Family available at www.cshperspectives.org

Copyright (C) 2010 Cold Spring Harbor Laboratory Press; all rights reserved; doi: 10.1101/cshperspect.a004887

Cite this article as Cold Spring Harb Perspect Biol 2010;00:a004887 
V. Dötsch et al.

A

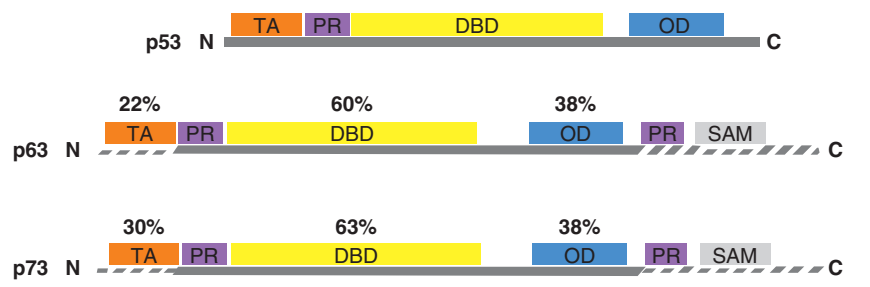

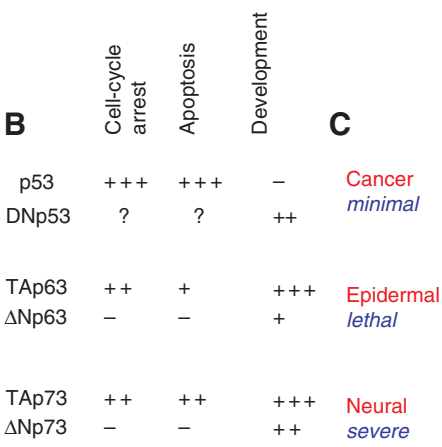

Figure 1. Schematic representation of the protein modular structure of the p53 family members. $(A)$ The p53 family includes three genes that encode $\mathrm{p} 53, \mathrm{p} 73$, and $\mathrm{p} 63$. The overall domain structure of $\mathrm{p} 53, \mathrm{p} 73$, and p63 is conserved and consists of an amino-terminal transactivation domain (TAD), a central DNA binding domain (DBD) and a carboxy-terminal oligomerization domain (OD). The longest $\alpha$ isoform of p73 and p63 contains a sterile alpha motif (SAM), a putative protein-protein interaction domain found in many signaling proteins and transcription factors. Identity shared by p73 and p63 with p53 is indicated. $(B)$ Simplified classification of the functions of the p53 family members. Members of this family are involved in similar as well as in unique cellular functions, with the most important role of p63 and p73 being regulation of differentiation and development. Their crucial and specific functions in controlling development and differentiation are well exemplified by the p63 and p73 knockout mouse developmental phenotypes (C).

isoforms act as inhibitors of the active family members. Hence, the structural complexity that distinguishes these proteins, confers molecular flexibility, and determines a corresponding functional diversity within the family.

As a consequence, although p63 and p73 share many functional properties of p53, and cooperate with p53 in the regulation of tumorigenesis, in the absence of stress, the most important role of these p 53 family members is regulation of differentiation and development. Indeed, both p63 and p73 exhibit distinct and unique biological functions. 063 plays a relevant role in the development of squamous epithelia and their derivatives, while p73 is indispensable for neuronal differentiation and the development of nervous and olfactory systems. Consistently, p63 and p73 deficient mice manifest severe limb truncations, absence of skin, hair, teeth, mammary, lachrymal, and salivary glands (Mills et al. 1999; Yang et al. 1999) and complex defects in neuronal development (Yang et al. 2000; Pozniak et al. 2000), respectively. As a result, imbalance within the p53 protein family contributes to a significant proportion of congenital developmental abnormalities in humans.

\section{STRUCTURAL FEATURES OF THE FAMILY MEMBERS}

The p53 family members are modular proteins with a similar basic structure, which is schematically depicted in Figure 1. There are three major domains, which are highly conserved between the family members. The TAD is the least conserved with $22 \%$ identity between p63 and p53 and 30\% between p73 and p53. The core DNA binding domain (DBD) of p63 and p73 are $60 \%$ and $63 \%$ identical with p53 respectively. In addition, the residues of p53 that directly interact with DNA are identical in p63 and p73. Consequently, both p63 and p73 can bind to canonical p53 DNA-binding sites and activate transcription from $\mathrm{p} 53$-responsive promoters, thus inducing cell cycle arrest, apoptosis and cellular senescence (Jost et al. 1997; Yang et al. 1998; De Laurenzi et al. 1998, Melino et al. 2004; Keyes et al. 2005). The carboxy-terminal oligomerization domain (OD) of p53 is 38\% identical with p63 and p73.

p63 and p73 exist as multiple functionally diverse proteins that originate from a combination of alternative promoter usage and alternative splicing (De Laurenzi et al. 1998; De 
Laurenzi et al. 1999; Grob et al. 2001). The p63 and p73 genes encode several distinct protein isoforms generated by alternative splicing at the carboxy-terminal, giving rise to three p63 variants $(\alpha-\gamma)$ (Yang et al. 1998) and at least six different p73 terminal variants $(\alpha-\zeta)$ (De Laurenzi et al. 1998; De Laurenzi et al. 1999). Interestingly, the p53 gene has recently been found to also generate multiple protein variants as a result of alternative splicing (Bourdon et al. 2005). The carboxy-terminal isoforms differ in their ability to transactivate gene expression (Zhu et al. 1998; De Laurenzi et al. 1999; Lee and La Thangue 1999; Shimada et al. 1999). The full-length proteins (denoted as $\alpha$ isoforms) of $\mathrm{p} 63$ and $\mathrm{p} 73$ contain a carboxy-terminal sterile $\alpha$-motif (SAM) domain, involved in protein-protein interaction, and a transcription inhibition domain (TID), that decreases their transcriptional activity (Serber et al. 2002; Straub et al. 2009) by enforcing a closed conformation through the interaction with the amino-terminal transactivation domain.

Additionally, the p63 and p73 genes have two distinct promoters; the first promoter (P1) yields a full-length protein possessing an aminoterminal TAD (TA isoforms), the second promoter (P2), located within intron 3 , gives rise to amino-terminally truncated proteins $(\Delta \mathrm{N}$ isoforms). The latter lack the amino-terminal TAD and, as a result, they act as dominant negative inhibitors of p53 and the full-length TA variants (Grob et al. 2001; Stiewe et al. 2002; Nakagawa et al. 2002; Kartasheva et al. 2002). In addition, several other amino-terminally truncated p73 isoforms initiating at different ATGs have been described. Inhibition of p 53 by $\Delta$ Np73 involves competition for the DNA binding sites, whereas TAp73 can be inhibited by direct protein-protein interactions (Grob et al. 2001; Stiewe et al. 2002). In addition, TA proteins can directly activate the transcription of $\Delta \mathrm{N}$ isoforms (Nakagawa et al. 2003; Grob et al. 2001). Recent in vitro investigations of the isolated ODs of $\mathrm{p} 63$ and $\mathrm{p} 73$ have revealed that both proteins interact with each other and can form heterooligomers of all possible stoichiometries (Coutandin et al. 2009). Surprisingly, a heterotetramer consisting of two homodimers is the thermodynamically most stable form, suggesting that such heterocomplexes might exist in cells as well. Interestingly, Rocco et al. showed that the majority of TAp $73 \beta$ is physically bound to $\Delta \mathrm{Np} 63 \alpha$ in JHU 029 cells, a cell line derived from head and neck squamous cell carcinoma (Rocco et al. 2006). These examples show that the structural complexity of the p53 family and the reciprocal regulatory networks cause a complicated interplay between the family members and their isoforms.

Full-length and truncated isoforms of the p53 family generally exhibit reciprocal biological functions: truncated isoforms support proliferation while TA variants promote cell cycle arrest, cellular senescence and apoptosis. However, the activity of p63 and p73 proteins may also depend on the intracellular context. As an example, even though ectopic expression of TAp73 $\beta$ suppresses growth, this isoform can synergize with the proto-oncogene c-Jun to promote cellular survival (Vikhanskaya et al. 2007). Hence, the existence of $\mathrm{p} 53$ family proteins with opposing activity implies that the balance of various isoforms may determine cell fate.

\section{EVOLUTION OF THE p53 FAMILY MEMBERS}

Members of the p53 protein family are not only found in vertebrates but also in many invertebrate species including mollusks, insects, and worms. Recent structure determinations of the $\mathrm{DBD}$ as well as of the OD of different members of this protein family have started to shed some light onto the evolutionary path of p53 and its homologs. All members of the p53 protein family from all organisms that have been identified so far possesses a DBD which contains five sequence domains of high homology. The crystal structure of human p53 bound to a consensus p53 DNA sequence has revealed that these sequence domains contain the residues that are important for DNA binding as well as for coordinating a structurally important zinc ion (Cho et al. 1994; Huyen et al. 2004). Interestingly, the residues that contact DNA are very well conserved among all species and homologs. In the p53 sequences from several species, as well as the human p63 and p73 homologs, the 
V. Dötsch et al.

only difference among the residues that contact the DNA is the exchange of R283 of human p53, which makes a contact with the phosphate backbone of the DNA with a lysine. The p53 forms of two important model organisms, Caenorhabditis elegans (Derry et al. 2001; Schumacher et al. 2001) and Drosophila melanogaster (Brodsky et al. 2000; Ollmann et al. 2000) have been studied in greater detail, and both show additional changes. In the case of the Drosophila protein Dmp53, R273 of p53 is replaced by K259 and R283 with I269, while in the C. elegans protein Cep-1, S241 of p53 is replaced with K363 and C277 with Y401. In addition, a crystal structure of the isolated DBD of Cep-1 has been determined and shows structural changes in the three loops L1, L2, and L3 that are important for contacting DNA and stabilizing the entire structure (Huyen et al. 2004). Although these loops are devoid of secondary structure elements in p53, they contain small helices in Cep-1. Surprisingly, despite these structural and sequence differences between p53 and Cep-1, they both show almost the same sequence specificity. Both proteins differ slightly in their nucleotide preference only in position four of the five base pair consensus sequence (Huyen et al. 2004). All members of the p53 protein family that have been investigated so far demonstrate very similar binding specificities (Brodsky et al. 2000).

The high conservation of residues that contact DNA and of the DNA binding specificity suggests that the original function of this protein family reaches far back in evolution. Detailed analysis of the function of Cep-1 and Dmp53 has revealed that they are required for the activation of apoptosis of germ cells in response to DNA damage (Schumacher et al. 2005; Derry et al. 2007; Brodsky et al. 2004). Maintenance of genetic stability of germ cells seems to be the ancestral function of this protein family. Even invertebrates like C. elegans, which do not possesses renewable tissues, have a life span of $2 \mathrm{wk}$ and are therefore not threatened by tumors, have to monitor the genetic stability of their germ cells and eliminate those with damaged DNA. Interestingly, the recent discovery that TAp63 $\alpha$ is responsible for maintaining genetic stability in mammalian oocytes and eliminates damaged cells suggests that p63 is evolutionary the most ancient form (Suh et al. 2006). Later in evolution, p73 and, with the invention of renewable tissues, p53 appeared as a tumor suppressors in somatic cells. This step from a germ cell specific control mechanism to a more general surveillance system for somatic cells became probably necessary, since the average life-time of the individual now exceeded the average life time of a cell, thus making tissue renewal mandatory.

The evolutionary link between p63 and the ancient invertebrate homologs can also be seen at the structural level. Both p63 and p73 have isoforms that contain a carboxy-terminal SAM domain which is, however, missing in p53 (Chi et al. 1999). Structure determination of the region carboxy-terminal to the DBD of Cep-1 has demonstrated that Cep- 1 also contains a carboxy-terminal SAM domain (Ou et al. 2007) that, however, is closely linked to the OD (whereas $\sim 100$ amino acids separate the SAM domain from the OD in p63 and p73). Another characteristic feature of Cep-1 is that its OD can only form dimers and not tetramers as the mammalian p53 protein family members (Fig. 2).

In contrast to Cep-1, structure determination of the OD of the Drosophila protein Dmp53 has revealed a tetrameric structure that, however, shows an architecture different from the tetrameric p53 OD (Ou et al. 2007). Although the core of the domain is the same, every secondary structure element that is present in the p53 OD is doubled in the Dmp53 OD (Fig. 2). Removal of these additional secondary structure elements results in the disruption of the tetrameric state and conformational instability.

Interestingly, a recent structure determination of the OD of p73 and investigation of the OD of p63 have demonstrated that both proteins contain an additional carboxy-terminal helix that is not present in p53 and that is necessary to keep the OD of p73 in a tetrameric and conformational stable state (Coutandin et al. 2009) (see Fig. 2). These results show that the OD of p53 that for a long time was thought to be the prototype of all ODs of the 


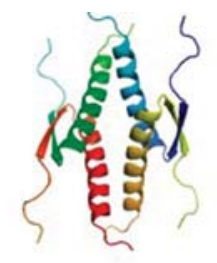

p53

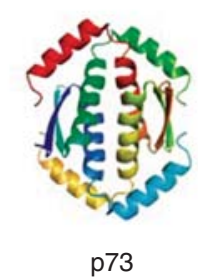

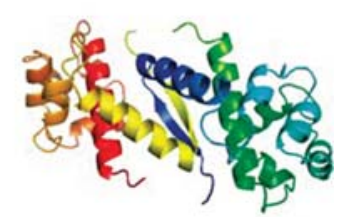

Cep-1

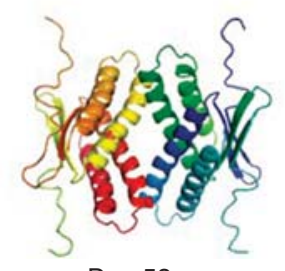

Dmp53
Figure 2. Structures of the ODs of p53, Cep-1 (C. elegans), p73 and Dmp53 (Drosophila melanogaster). The p53 OD is a tetramer of dimers in which each monomer contributes one $\beta$-strand and one $\alpha$-helix. Dimers are assembled by the formation of an intermolecular antiparallel $\beta$-sheet, which is stabilized by hydrophobic interactions with two helices that also arrange in an antiparallel orientation. The tetramer is created by hydrophobic interactions between the helices of both dimers. In the case of p73 this arrangement is further stabilized by a second helix that reaches across the tetramerization interface. In the Drosophila protein Dmp53, every secondary structure element is doubled, and in Cep-1, tetramerization is inhibited by charged amino acids in the tetramerization interface. The dimeric structure of Cep-1 is stabilized by interaction with a SAM domain (one for each monomer).

entire family is the only one that is conformationally stable without additional domains (Cep-1) or additional secondary structure elements (Dmp53, p73, p63) (Coutandin et al. 2009; Andreas et al. 2009). These findings suggest an evolutionary path from dimeric proteins, that monitor the genetic stability in germ cells of invertebrates, to the tetrameric p63 and p73 forms in mammals, that mainly have developmental functions, and finally to the tetrameric tumor suppressor p53.

\section{ROLE OF THE P53 FAMILY MEMBERS IN TUMORIGENESIS}

The most studied role of the p53 family is likely the regulation of tumor suppression. Unlike p63 and p73, the Ancestors of p53

$\mathrm{p} 53$, which is frequently mutated or inactivated during tumorigenesis (in over $50 \%$ of human tumors), p63 and p73 are rarely mutated in human cancers $(<1 \%)$, thus excluding them as classic Knudson-type tumor suppressor genes (Melino et al. 2002; Melino et al. 2003). Nevertheless, emerging evidence indicates that they may contribute to tumorigenesis.

Unlike p53 null mice, which manifest increased susceptibility to spontaneous and experimentally induced tumors, $\mathrm{p} 63$ and $\mathrm{p} 73$ loss does not result in increased tumorigenesis in vivo (Yang et al. 2000; Mills et al. 1999; Yang et al. 1999). However, the availability of knockout animals deficient for multiple p63 and p73 isoforms with potentially opposing roles has greatly complicated the assignment of specific in vivo functions to individual variants. In addition, the phenotypical characterization of these knockout mice has been further complicated by severe developmental problems (see following paragraph), leading to premature death that precluded observations of enhanced tumorigenesis.

A study examining the tumorigenic effects of p63 and p73 in aging heterozygous mice has provided indication that both cooperate with p53 in tumor suppression (Flores et al. 2005). $\mathrm{p} 73^{+/-}$and $\mathrm{p} 63^{+/-}$mice developed a broad spectrum of malignant lesions with a long latency averaging 15 months and, concomitantly, generally exhibited loss of heterozygosity. In addition, double mutant heterozygous $\left(\mathrm{p} 53^{+/-} / \mathrm{p} 73^{+/-}\right.$or $\left.\mathrm{p} 53^{+/-} / \mathrm{p} 63^{+/-}\right)$mice displayed a higher tumor burden and increased tumor metastasis, compared with $\mathrm{p} 53^{+/-}$mice (Flores et al. 2005).

Whether or not TAp73 is a tumor suppressor has been difficult to prove decisively until mice selectively deficient for the TA isoforms of p73 were available (Tomasini et al. 2008). Phenotypical characterization of this animal model revealed that predisposition to spontaneous and carcinogen-induced tumorigenesis is increased by specific TAp73 loss in vivo (Tomasini et al. 2008). In addition a second major phenotype of the TAp73 selective knockout animals is infertility because of genomic instability of the oocyte (see also following paragraphs), 
V. Dötsch et al.

further revealing a role for TAp73 as a tumor suppressor in maintaining the fidelity of the genome. This and other studies (Tomasini et al. 2009) pointed out that $p 73$ participates in the formation of the proper mitotic and meiotic spindles required for chromosome alignment and genomic stability. The influence of TAp73 on the spindle assembly checkpoint relies on its ability to potentiate BubR1 activity. Thus, in the absence of TAp73, cells have a reduced ability to initiate and maintain proper mitotic arrest as a result of insufficient BubR1 function, ultimately leading to genomic instability. The involvement of p73 in mitotic regulation has been corroborated by the observation that $\mathrm{p} 73$ controls mitotic cell death, observed in Bub1-deficient cells and induced by conditions that activate the spindle checkpoint (Niikura et al. 2007).

Several evidences indicate that p63 may also contribute to tumorigenesis. Indeed, in vitro studies performed on squamous cell carcinoma (SCC) cell lines showed that disruption of p63 causes up-regulation of genes associated with a higher potential to metastasize and invade (Barbieri et al. 2006). Recently, it has been demonstrated a primary role for p63 as antagonist of TGF $\beta$ driven tumor invasiveness and metastasis. Mutant p53 and Smad intercept p63 to form a ternary complex, in which p63 transcriptional functions are antagonized. Thus in the presence of mutant $\mathrm{p} 53$, TGF $\beta$ controls $\mathrm{p} 63$ functions (Adorno et al. 2009). On the other hand, there are evidences suggesting that, because $\Delta$ Np63 plays a fundamental role in development of epithelia, its alterations are involved in the development of epithelial tumors. Thus $\Delta \mathrm{Np} 63$ functions as an oncogene. More specifically, SCCs of the lung and head and neck are characterized by high-level amplification of the p63 locus as well as overexpression of $\Delta \mathrm{Np} 63 \alpha$ isoform (Crook et al. 2000; Hibi et al. 2000; Yamaguchi et al. 2000). Bladder, breast, and more aggressive cases of prostate cancers (adenoid cystic/basal cell carcinoma) also have a marked overexpression of $\Delta \mathrm{Np} 63$. In addition, $\Delta \mathrm{Np} 63 \alpha$ overexpression leads to enhanced cell growth in soft agar, and increased tumor size in mice. The molecular mechanisms through which $\Delta \mathrm{Np} 63$ promotes epithelial tumor growth are currently under investigation, suggesting that the role of p63 in epithelial tumorigenesis is clearly complex and needs further clarification.

According to the most accredited model, imbalance between TA and $\Delta \mathrm{N}$ isoforms of the p53 family members may lead to tumorigenesis by preventing transcriptionally active isoforms from engaging in tumor-suppressive functions (Casciano et al. 2002; Puig et al. 2003; Concin et al. 2004). Recent data have indeed implied that relative $\Delta \mathrm{N}$ isoforms overexpression may confer a proliferative advantage and tumorigenic potential to cancer cells by counteracting the cell-cycle arrest and proapoptotic transcriptional activities of $\mathrm{p} 53$ and TA proteins (Crook et al. 2000; Nylander et al. 2002; Rocco et al. 2006). Prognosis, disease-free survival and chemotherapeutic response in a number of human cancers are worse when the levels of the antiapoptotic and oncogenic $\Delta \mathrm{Np} 63 / 73$ isoforms are elevated as compared to the TA variants, or when tumors specifically lose TA isoform expression (Concin et al. 2004; Casciano et al. 2002; Puig et al. 2003; Urist et al. 2002). Thus, the full-length p 53 family members are inactivated by inhibitory isoforms.

The data published so far indicate a clear involvement of p73 in tumorigenesis, especially of TAp73 as a tumor suppressor, but also of both isoforms as regulators of the cell death pathway. Indeed, p73 isoforms seem to act as prognostic factors, predicting chemosensitivity. Still several crucial questions are open for future work. For example, the role of $\Delta \mathrm{Np} 73$ in cancer initiation and development is under investigation, both in tumor samples and in transgenic mouse models. Is p73 involved in senescence of cancer cells? Similarly, both isoforms of p63 are deregulated in cancer, and transgenic mouse models show a clear cancer-prone phenotype. But is its involvement merely based on apoptosis regulation, or does p63 act on cancer stem cells? Is chromosomal instability also affected by $\mathrm{p} 63$, and how?

\section{UNIQUE FUNCTIONS OF p73 AND p63}

Though the p53 family proteins share similar domain architecture and sequence identity, 
p63 and p73, the Ancestors of p53

and the TA variants all can activate apoptosis in response to DNA damaging insults, the outcome of their ablation in vivo is strikingly different. Indeed, p63 and p73 exhibit distinct and unique biological functions, possibly reflecting their numerous isoforms, and revealed by their knockout phenotypes (see Fig. 1). Both knockout mice show major and specific developmental defects (Mills et al. 1999; Yang et al. 1999; Yang et al. 2000). In the p53 family, deficiency of p63 has the most striking effect on development (Mills et al. 1999; Yang et al. 1999).

\section{Role of p63 in Skin and Epithelial Development}

Despite its structural similarity to p53, the central role of p63 in epidermal development, as opposed to tumor susceptibility, became established with the publication of two independent studies on $\mathrm{p} 63^{-/-}$mouse models, generated by disrupting exons common to both TA and $\Delta \mathrm{N}$ isoforms (Yang et al. 1999; Mills et al. 1999). Both mice were born alive, but died within hours after birth because they fail to develop skin. $\Delta \mathrm{Np} 63$ isoforms are strongly expressed in epithelial cells with high clonogenic and proliferative capacity, and p $63^{-}$- epithelial stem cells undergo premature proliferation rundown, both in epidermis and thymus, indicating that p63 is a key determinant of the proliferative capacity of epithelial stem cells (Senoo et al. 2007). Indeed, a detailed analysis of the expression of $\mathrm{K} 5$ and loricrin in the epidermis of E16 wild type and $\mathrm{p} 63^{-/-}$mice, revealed that cells remaining on the surface of the p63 embryos are committed to an epidermal lineage that progresses through differentiation. Similar evidences were obtained using a different approach (Candi et al. 2006). By crossing TAp63 $\alpha$ or $\Delta \mathrm{Np} 63 \alpha$ epidermal transgenic mice into $\mathrm{p} 63^{-/-}$mice, we generated animals expressing only one single isoform to identify the relative contribution of each variant to the development of the epidermis and thymic epithelial compartment (Candi et al. 2006; Candi et al. 2007). Although we were unable to obtain a full reversion of the phenotype of the knock out mice, the study showed that transgenic animals complemented with $\Delta \mathrm{Np} 63$ $\left(\mathrm{p} 63^{-/-} ; \Delta \mathrm{N}\right)$ developed a significant epidermal basal layer, while transgenic mice complemented with TAp63 (p63 ${ }^{-/}$;TA) did not differ from $\mathrm{p} 63^{-/}$mice. Double complemented mice exhibited a greater degree of re-epithelialization, with expression of keratins of the basal layer (K5 and K14), and differentiation-specific markers such as $\mathrm{K} 1$ and loricrin, but complete cornification remained impaired (Candi et al. 2006). These data suggested that $\Delta \mathrm{Np} 63$ is important for maintaining the proliferative potential of the basal layer, whereas TAp63 contributes to epidermal differentiation by acting synergistically with and/or subsequently to $\Delta$ Np63 (Fig. 3). Furthermore, these results are consistent with a study based on RNA interference directed against p63 isoforms, in which the authors demonstrated that $\Delta \mathrm{Np} 63$ isoforms are the main mediators of p63 effects, and that TAp63 isoforms contribute to later stages of differentiation in mature keratinocytes. In the same work, the roles of p63 in differentiation and cell proliferation were shown to be distinct. Indeed, downregulation of p63 causes a cell cycle arrest in keratinocytes that is p53-dependent (Truong et al. 2006; Lee et al. 2002). Simultaneous knockdown of p53 in the context of p63 loss is able to rescue cell proliferation, however the differentiation defect is still present (Truong et al. 2006). The identification of target genes is crucial to understand p63 function. Several approaches have been taken over the last few years. These studies provided clear evidences that p63 controls and connects different pathways in keratinocytes (Pozzi et al. 2009), involving differentiation, adhesion, and proliferation (Fig. 3).

Though the original controversy on $\Delta \mathrm{Np} 63$ being involved in stemness or differentiation has been solved, still the underlying molecular mechanisms involved await elucidation. Even though TAp63 is not expressed in the epidermis, it is induced under stress and during wound healing, indicating a role in stemness, like its other isoform, as well as in controlling cell death (Lin et al. 2009). Clearly, these themes leave lot of space for future development. 
V. Dötsch et al.
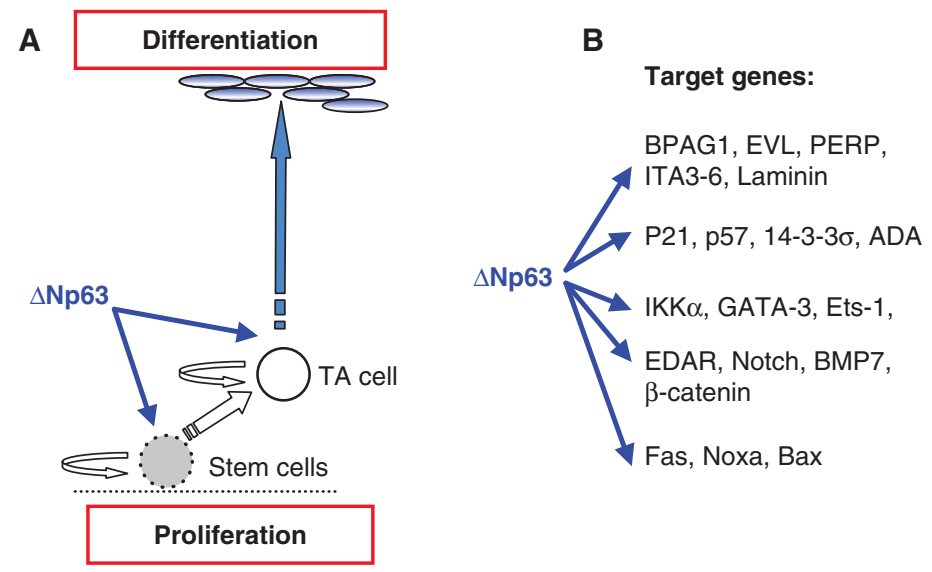

Functions:

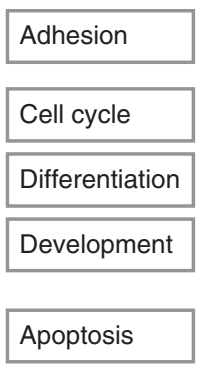

Figure 3. Role of p63 in epidermal formation. (A) The epidermis is maintained throughout adult life by stem cells, which self-renew and produce progeny (TA cells) that undergoes terminal differentiation. TA and stem cells are located in the epidermal basal layer. A simplified scheme of the actions of p63 in epidermal development is shown here. $(B)$ Several studies have been performed to identify the target promoters of p63. Here is shown a simplified and limited list of published p63 target genes that have been experimentally validated. The scheme does not necessarily imply that other target genes may be less important.

\section{Role of p73 in Neuronal Development and Differentiation}

Mice functionally deficient for the p73 gene are viable. The vast majority of the $\mathrm{p} 73^{-/-}$mice die before 4 wk of age with only $25 \%$ of them reaching adulthood (Yang et al. 2000). At birth, p73 deficient mice manifest hippocampal dysgenesis due to massive apoptosis of sympathetic neurons in superior cervical ganglion, leading to an approximately $40 \%$ cell loss (Pozniak et al. 2000). Later on, they display hypersecretion of cerebrospinal fluid resulting in hydrocephalus, as well as runting, and abnormal social and reproductive behavior because of defects in pheromone detection. In addition, $\mathrm{p} 73^{-/-}$ mice have immunological problems characterized by chronic infections and inflammation. Characterization of embryos overexpressing amino-terminally truncated isoforms of p73 has demonstrated that deregulated expression of $\Delta \mathrm{Np} 73 \alpha$ causes early embryonic lethality at E6.5-E8.0, and gastrulation defects (Erster et al. 2006).

The neuronal defects manifested by the p73 $3^{-/}$mice have uncovered a master role for p73 in the developing neuronal cells as well as in mature nervous system in the long-term maintenance of adult neurons. The prosurvival role of p73 during nervous system development has been ascribed to the predominant expression of the antiapoptotic $\Delta \mathrm{Np} 73$ isoforms in normal developing brain and sympathetic ganglia (Fig. 4) (Pozniak et al. 2000; Yang et al. 2000). In response to NGF withdrawal, the basal levels of $\Delta \mathrm{Np} 73$ decline dramatically, thus allowing neurons to undergo cell death during nervous system development (Fig. 4). In addition, if the absence of $\Delta \mathrm{Np} 73$ is rescued by ectopic expression of this isoform, neurons are protected from apoptosis.

The neuronal defects observed in the p73 knockout mice are therefore a result of the absence of the $\Delta \mathrm{Np} 73$ isoforms that normally block p53/TAp73/TAp63-mediated apoptosis in developing neurons (Fig. 4) (Jacobs et al. 2005; Pozniak et al. 2000). An in vivo validation of the antagonistic effects exerted by $\Delta \mathrm{Np} 73$ on $\mathrm{p} 53$ proapoptotic function comes from the analysis of the p73/p53 double knockout mice, in which the augmented death of sympathetic neurons observed in p73 mutant animals was at least partially rescued by loss of p53 (Lee et al. 2004). The limited rescue observed in these animals can be explained by the presence in sympathetic neurons of the third family 
A

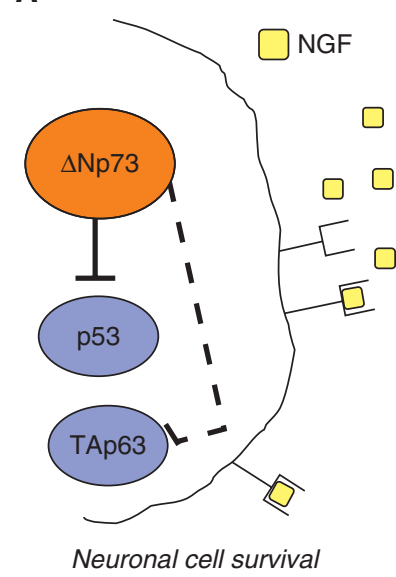

B

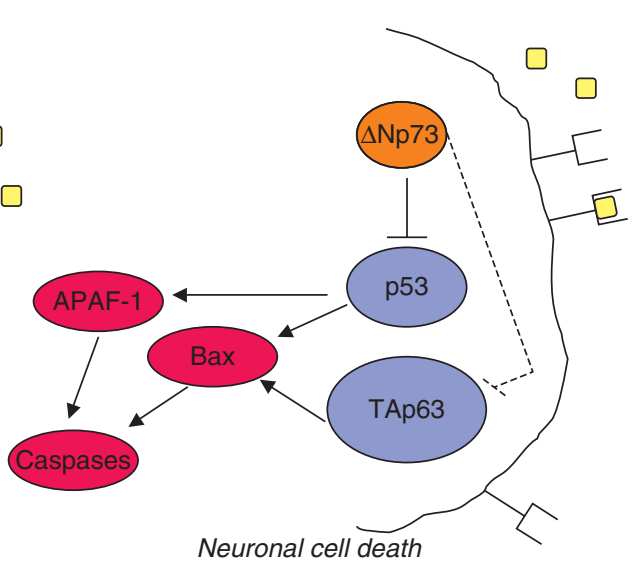

Figure 4. Regulation of developmental sympathetic neuronal survival and apoptosis by the p53 family members. The p53 protein family has been implicated in the death signaling following NGF withdrawal. $\Delta$ Np73 is an NGF-induced anti-apoptotic protein in sympathetic neurons. (A) During development, neuronal survival is guaranteed by the availability of NGF, which in turn maintains the $\Delta$ Np73 levels high enough to inhibit the pro-apoptotic functions of both p53 and TAp63. (B) On the other hand, once the levels of NGF becomes restrictive, neuronal cells are committed to cell death through down-regulation of $\Delta \mathrm{Np} 73$ and augmented TAp63. Under these circumstances, the antagonistic action of $\Delta \mathrm{Np} 73$ is released, and the proapototic family members can elicit cell death by initiating mitochondrial apoptosis.

member, TAp63, whose expression increases in parallel with apoptosis (Fig. 4) (Jacobs et al. 2005). Further experimental evidences have implicated TAp63 in developmental sympathetic neuron death (Jacobs et al. 2005; Nicotera and Melino 2005). Indeed, adenoviral expression of TAp63 is per se sufficient to cause sympathetic neuron cell death, even in the presence of NGF, and cultured $\mathrm{p} 63^{-/-}$sympathetic neurons are resistant to NGF withdrawal-elicited apoptosis.

A further involvement of the p53 family in regulating cell survival has been described in adult neurons, which acquire intrinsic survival mechanisms, based on increased relative ratio of $\Delta \mathrm{Np} 73$ to p53 (Walsh et al. 2004). Consistently, the analysis of the sympathetic nervous system of $\mathrm{p} 73^{-/-}$adult mice revealed a dramatic decrease in cortical neuron number by postnatal day 14 into adulthood, when animals manifest thinned cortical hemispheres and enlarged ventricles (Pozniak et al. 2002). In addition, following axonal injury, p73 heterozygous neurons are more vulnerable than wild-type counterpart either in culture or in vivo (Walsh et al. 2004).
From this overview, becomes clear that ultimate survival of sympathetic neurons during embryogenesis and adult life strictly depends on a precise balance between the pro- versus the antiapoptotic p53 family members.

p73 has been additionally implicated in differentiation of neuroblastoma cells (De Laurenzi et al. 2000; Billon et al. 2004). Endogenous TAp73 levels rise in neuroblastoma cells that have been induced to differentiate by retinoic acid and ectopic expression of TAp73 isoforms induce neuronal differentiation. TAp73 may support differentiation by antagonizing Notch signaling in neuroblastoma cells and in primary neurons (Hooper et al. 2006). These data suggest that p73 is not merely regulating the cell death pathway, but actively participate to neurodevelopment, leaving further pathways to be clarified in the future.

\section{Role of TAp73 and TAp63 in Oocyte Function}

As previously mentioned, selective TAp73 knock out mice are sterile (Tomasini et al. 2008). Unlike p73 global knock out mice, in 


\section{Dötsch et al.}

which defects in sensory and hormonal pathways contribute to reproductive and behavioral phenotypes that lead to both male and female infertility, TAp $73^{-/-}$mice mate normally. Although displaying normal cyclicity, TAp $73^{-/-}$ females manifest a deficit in ovulated oocytes. Analysis of TAp $73^{-/-}$oocytes revealed a striking increase in spindle organization abnormalities that, ultimately, lead to impaired preimplantation embryonic development. Interestingly, natural aging abolishes TAp73 expression in oocytes (Tomasini et al. 2008), suggesting that loss of TAp73 may be responsible for the compromised developmental capacity of aged normal oocytes.

The TAp63 isoform has also been shown to be constitutively expressed in female germ cells during meiotic arrest, and is essential (after posttranslational modification) for DNA damage-induced oocytes death independently of p53 (Suh et al. 2006). Recently, the kinase regulating p63 in oocytes has been identified as c-Abl, and indeed, c-Abl inhibitors (Gleevec, Imitaninb) prevent oocyte loss during chemotherapy (Gonfloni et al. 2009). Is this useful for chemotherapy or should these damaged oocytes be eliminated?

This is an extremely relevant finding for the entire p53 family (Belyi and Levine 2009).
Indeed, Frank McKeon raised the concept that p63 is the guardian of the female germ line.

\section{HUMAN CONGENITAL GENETIC ABNORMALITIES ARISING FROM DYSFUNCTION OF p63}

Given the role played by the $\mathrm{p} 53$ family proteins as master regulators of crucial developmental processes, one would expect that their dysfunction or imbalance may lead to pathological abnormalities in humans. Although p73-based syndromes have not been identified yet, an extensive literature exists, supporting a crucial role for p63 in the pathogenesis of several human diseases.

Germ line mutations of p63 are found in humans and cause rare autosomal dominant developmental diseases, such as EEC syndrome (Ectrodactyly-ectodermal dysplasia-clefting), Hay-Wells (AEC) syndrome, Limb mammary syndrome, ADULT syndrome, Rapp-Hodgkin syndrome and nonsyndromic split hand split (SHSF) foot malformation (see Fig. 5). Collectively, the prevalence of ectodermal dysplasia syndromes (ED) is estimated at seven cases in 10,000 births. It is clinically characterized by ectodermal dysplasia affecting skin, hair, nails and teeth, and by facial clefts. In addition, EEC patients show lachrymal duct abnormalities,

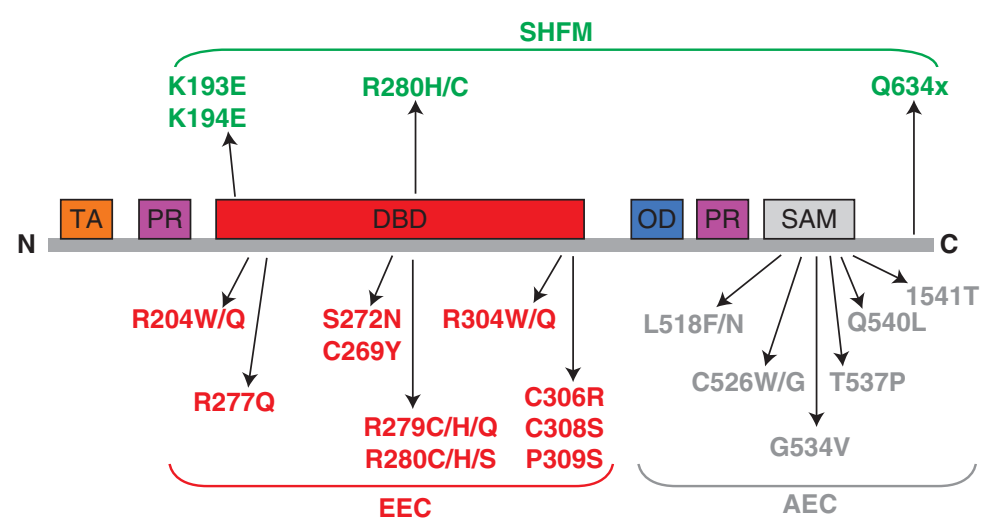

Figure 5. p63 mutations in human syndromes. p63 mutations in the EEC and AEC syndromes cluster respectively in DBD and SAM domains. Conserved protein domains are shown for TAp63: orange, TA domain; red, DNA-binding domain (DBD); blu, isomerization domain (OD); purple, proline-rich regions $(\mathrm{PR})$; gray, SAM domain. Heterozygous missense mutations identified in EEC, AEC, and SHFM syndromes are indicated. All AEC mutations are located in the SAM domain, whereas all missense mutations in EEC syndrome are in the DNA-binding domain. 
p63 and p73, the Ancestors of p53

urogenital problems, hearing loss, facial dimorphism, respiratory infections, and developmental retardation (Celli et al. 1999). Most commonly, these mutations give rise either to amino acid substitutions in the DBD (see later) that abolish p63 DNA binding ability, or to shifts of the reading frame, which specifically truncate the $\alpha$ isotype of p63 (Celli et al. 1999). AEC patients present mutations giving rise to amino acid substitutions in the SAM domain (McGrath et al. 2001). These missense mutations are predicted to disrupt protein-protein interactions, by either destroying the compact globular structure of the SAM domain, or substituting amino acids, which are crucial for such interactions. Further interpretation of the biological consequences of the SAM domain mutations is obscured by our lack of knowledge of the physiological role of this structural domain. Mutated proteins have been shown to act as dominant negative molecules and, in fact, the disease occurs at heterozygous level. Mutations in the p63 carboxy-terminal-end cause SHF malformation. Several of these mutations lead to truncated forms of the protein that are shortened by eight (Q634X) or three (E639X) amino acids (Rinne et al. 2009). These truncations remove a sumoylation site that seems to play an important role in the regulation of p63 (Ghioni et al. 2005; Huang et al. 2004; Straub et al. 2009). A striking genotype/phenotype correlation can be recognized (van Bokhoven and Brunner 2002; Rinne et al. 2006; Rinne et al. 2007) (Fig. 5). The pattern of mutations has revealed p63 protein domains that are particularly important for skin development (the carboxyterminal SAM domain), whereas other domains are crucially important for limb development (DBD, carboxy-terminal-end domain). The underlying molecular mechanisms leading to these diseases are under active investigation.

\section{CONCLUSIVE REMARKS}

Though discovered more than ten years ago, only more recently the biological roles of p63 and p73, which have been, at least partially, unveiled by their knock out developmental phenotypes, have started to be dissected into their functional complexity. During the past decade, a number of experimental and clinical discoveries (e.g., existence of multiple protein variants, displaying similar or antagonistic activities; structure determinations; overexpression of oncogenic $\Delta \mathrm{Np} 63 / 73$ isoforms in human cancers) in the field of the p53 family, and the availability of different mouse models (e.g. isoform-specific knock out animals), have much helped at improving the knowledge on their physiological as well as pathological functions. Additional studies involving selective knock out mice for specific p63 and p73 isoforms will continue to yield insights into their unique roles as well as into the interplay between the p53 family of transcription factors. Furthermore, the validation of TAp73 and TAp63 as tumor suppressors may offer novel and intriguing therapeutic approaches to enhance the chemosensitivity of tumor cells harboring mutated or inactivated p53.

\section{REFERENCES}

Adorno M, Cordenonsi M, Montagner M, Dupont S, Wong C, Hann B, Solari A, Bobisse S, Rondina MB, Guzzardo V, et al. 2009. A Mutant-p53/Smad complex opposes p63 to empower TGF $\beta$-induced metastasis. Cell 137: 87-98

Andreas CJ, Sridharan R, Eviatar N, Dmitry BV, Carol VR, et al. 2009. Structural evolution of p53, p63, and p73: Implication for heterotetramer formation. PNAS, in press.

Barbieri CE, Tang LJ, Brown KA, Pietenpol JA. 2006. Loss of p63 leads to increased cell migration and up-regulation of genes involved in invasion and metastasis. Cancer Res 66: 7589-7597.

Belyi VA, Levine AJ. 2009. One billion years of p53/p63/p73 evolution. Proc Natl Acad Sci 106: 17609-17610.

Billon N, Terrinoni A, Jolicoeur C, McCarthy A, Richardson WD, Melino G, Raff M. 2004. Roles for p53 and p73 during oligodendrocyte development. Development 131: $1211-1220$.

Bourdon JC, Fernandes K, Murray-Zmijewski F, Liu G, Diot A, Xirodimas DP, Saville MK, Lane DP. 2005. p53 isoforms can regulate $\mathrm{p} 53$ transcriptional activity. Genes Dev 19: 2122-2137.

Brodsky MH, Nordstrom W, Tsang G, Kwan E, Rubin GM, Abrams JM. 2000. Drosophila p53 binds a damage response element at the reaper locus. Cell 101: 103-113.

Brodsky MH, Weinert BT, Tsang G, Rong YS, McGinnis NM, Golic KG, Rio DC, Rubin GM. 2004. Drosophila melanogaster $\mathrm{MNK} / \mathrm{Chk} 2$ and p53 regulate multiple DNA repair and apoptotic pathways following DNA damage. Mol Cell Biol 24: 1219-1231. 
V. Dötsch et al.

Candi E, Rufini A, Terrinoni A, Dinsdale D, Ranalli M, Paradisi A, De Laurenzi V, Spagnoli LG, Catani MV, Ramadan S, et al. 2006. Differential roles of p63 isoforms in epidermal development: selective genetic complementation in p63 null mice. Cell Death Differ 13: 1037-1047.

Candi E, Rufini A, Terrinoni A, Giamboi-Miraglia A, Lena AM, Mantovani R, Knight R, Melino G. 2007. DeltaNp63 regulates thymic development through enhanced expression of FgfR2 and Jag2. Proc Natl Acad Sci U S A 104: 11999-12004.

Casciano I, Mazzocco K, Boni L, Pagnan G, Banelli B, Allemanni G, Ponzoni M, Tonini GP, Romani M. 2002. Expression of DeltaNp73 is a molecular marker for adverse outcome in neuroblastoma patients. Cell Death Differ 9: 246-251.

Celli J, Duijf P, Hamel BC, Bamshad M, Kramer B, Smits AP, Newbury-Ecob R, Hennekam RC, Van Buggenhout G, et al. 1999. Heterozygous germline mutations in the p53 homolog p63 are the cause of EEC syndrome. Cell 99: 143-153.

Chi SW, Ayed A, Arrowsmith CH. 1999. Solution structure of a conserved C-terminal domain of p73 with structural homology to the SAM domain. EMBO J, 18: 4438-4445.

Cho Y, Gorina S, Jeffrey PD, Pavletich NP. 1994. Crystal structure of a p53 tumor suppressor-DNA complex: Understanding tumorigenic mutations. Science 265: 346-355.

Concin N, Becker K, Slade N, Erster S, Mueller-Holzner E, Ulmer H, Daxenbichler G, Zeimet A, Zeillinger R, Marth C, et al. 2004. Transdominant DeltaTAp73 isoforms are frequently up-regulated in ovarian cancer. Evidence for their role as epigenetic p53 inhibitors in vivo. Cancer Res 64: 2449-2460.

Coutandin D, Löhr F, Niesen FH, Ikeya T, Weber TA, Schäfer B, Zielonka EM, Bullock AN, Yang A, Güntert P, et al. 2009. Conformational stability and activity of p73 require a second helix in the tetramerization domain. Cell Death Differ, in press.

Crook T, Nicholls JM, Brooks L, O'Nions J, Allday MJ. 2000 High level expression of deltaN-p63: A mechanism for the inactivation of p53 in undifferentiated nasopharyngeal carcinoma (NPC). Oncogene 19: 3439-3444.

De Laurenzi V, Costanzo A, Barcaroli D, Terrinoni A, Falco M, Annicchiarico-Petruzzelli M, Levrero M, Melino G. 1998. Two new $\mathrm{p} 73$ splice variants, $\gamma$ and $\delta$, with different transcriptional activity. J Exp Med 188: 1763-1768.

De Laurenzi VD, Catani MV, Terrinoni A, Corazzari M, Melino G, Costanzo A, Levrero M, Knight RA. 1999. Additional complexity in p73: Induction by mitogens in lymphoid cells and identification of two new splicing variants $\varepsilon$ and $\zeta$. Cell Death Differ 6: 389-390.

De Laurenzi V, Raschella G, Barcaroli D, AnnicchiaricoPetruzzelli M, Ranalli M, Catani MV, Tanno B, Costanzo A, Levrero M, Melino G. 2000. Induction of neuronal differentiation by $\mathrm{p} 73$ in a neuroblastoma cell line. J Biol Chem 275: 15226-15231.

Derry WB, Putzke AP, Rothman JH. 2001. Caenorhabditis elegans p53: Role in apoptosis, meiosis, and stress resistance. Science 294: 591-595.

Derry WB, Bierings R, van Iersel M, Satkunendran T, Reinke V, Rothman JH. 2007. Regulation of developmental rate and germ cell proliferation in Caenorhabditis elegans by the p53 gene network. Cell Death Differ 14: 662-670.

Erster S, Palacios G, Rosenquist T, Chang C, Moll UM. 2006. Deregulated expression of $\Delta \mathrm{Np} 73 \alpha$ causes early embryonic lethality. Cell Death Differ 13: 170-173

Flores ER, Sengupta S, Miller JB, Newman JJ, Bronson R, Crowley D, Yang A, McKeon F Jacks T. 2005. Tumor predisposition in mice mutant for $\mathrm{p} 63$ and $\mathrm{p} 73$ : evidence for broader tumor suppressor functions for the p53 family. Cancer Cell 7: 363-373.

Ghioni P, D’Alessandra Y, Mansueto G, Jaffray E, Hay RT, Mantia GL, et al. 2005. The protein stability and transcriptional activity of p $63 \alpha$ are regulated by SUMO-1 conjugation. Cell Cycle 4: 183-190.

Gonfloni S, Di Tella L, Caldarola S, Cannata SM, Klinger FG, Di Bartolomeo C, Mattei M, Candi E, De Felici M, Melino G, Cesareni G. 2009. Inhibition of the c-AblTAp63 pathway protects mouse oocytes from chemotherapy-induced death. Nat Med 15: 1179-1185.

Grob TJ, Novak U, Maisse C, Barcaroli D, Lüthi AU, Pirnia F, Hügli B, Graber HU, De Laurenzi V, Fey MF, et al. 2001. Human delta Np73 regulates a dominant negative feedback loop for TAp73 and p53. Cell Death Differ 8: 1213-1223.

Hibi K, Trink B, Patturajan M, Westra WH, Caballero OL, Hill DE, Ratovitski EA, Jen J, Sidransky D. 2000. AIS is an oncogene amplified in squamous cell carcinoma. Proc Natl Acad Sci U S A 97: 5462-5467.

Hooper C, Tavassoli M, Chapple JP, Uwanogho D, Goodyear R, Melino G, Lovestone S, Killick R. 2006. TAp73 isoforms antagonize Notch signalling in SH-SY5Y neuroblastomas and in primary neurones. $J$ Neurochem 99: 989-999.

Huang YP, Wu G, Guo Z, Osada M, Fomenkov T, Park HL, et al. 2004. Altered sumoylation of p63 $\alpha$ contributes to the split-hand/foot malformation phenotype. Cell Cycle 3: $1587-1596$.

Huyen Y, Jeffrey PD, Derry WB, Rothman JH, Pavletich NP, Stavridi ES, Halazonetis TD. 2004. Structural differences in the DNA binding domains of human $\mathrm{p} 53$ and its C. elegans ortholog Cep-1. Structure 12: 1237-1243.

Jacobs WB, Govoni G, Ho D, Atwal JK, Barnabe-Heider F, Keyes WM, Mills AA, Miller FD, Kaplan DR. 2005. P63 is an essential proapoptotic protein during neural development. Neuron 48: 743-756.

Jost CA, Marin MC, Kaelin WG Jr 1997. p73 is a simian [correction of human] p53-related protein that can induce apoptosis. Nature 389: 191-194.

Kaghad M, Bonnet H, Yang A, Creancier L, Biscan J-C, Valent A, Minty A, Chalon P, Lelias J-M, Dumont X, et al. 1997. Monoallelically expressed gene related to p53 at $1 \mathrm{p} 36$, a region frequently deleted in neuroblastoma and other human cancers. Cell 90: 809-819.

Kartasheva NN, Contente A, Lenz-Stoppler C, Roth J, Dobbelstein M. 2002. p53 induces the expression of its antagonist p73 $\delta \mathrm{N}$, establishing an autoregulatory feedback loop. Oncogene 21: 4715-4727.

Keyes WM, Wu Y, Vogel H, Guo X, Lowe SW, Mills AA. 2005. p63 deficiency activates a program of cellular senescence and leads to accelerated aging. Genes Dev 19: 1986-1999. 
Lee H, Kinelman D. 2002. A dominant negative form of p63 is required for epidermal proliferation in Zebrafish. Dev Cell 2: 607-616.

Lee CW, La Thangue NB. 1999. Promoter specificity and stability control of the p53-related protein p73. Oncogene 18: $4171-4181$.

Lee AF, Ho DK, Zanassi P, Walsh GS, Kaplan DR, Miller FD. 2004. Evidence that DeltaNp73 promotes neuronal survival by p53-dependent and p53-independent mechanisms. J Neurosci 24: 9174-9184.

Lin YL, Sengupta S, Gurdziel K, Bell GW, Jacks T, Flores ER. 2009. p63 and p73 transcriptionally regulate genes involved in DNA repair. PLoS Genet 5: e1000680.

McGrath JA, Duijf PH, Doetsch V, Irvine AD, de Waal R, Vanmolkot KR, Wessagowit V, Kelly A, Atherton DJ, Griffiths WA, et al. 2001. Hay-Wells syndrome is caused by heterozygous missense mutations in the SAM domain of p63. Hum Mol Genet 10: 221-229

Melino G, De Laurenzi V, Vousden KH. 2002. p73: Friend or foe in tumorigenesis. Nat Rev Cancer 2: 605-615.

Melino G, Bernassola F, Ranalli M, Yee K, Zong WX, Corazzari M, Knight RA, Green DR, Thompson C, Vousden KH. 2004. p73 Induces apoptosis via PUMA transactivation and Bax mitochondrial translocation. J Biol Chem. 279: $8076-8083$.

Melino G, Lu X, Gasco M, Crook T, Knight RA. 2003. Functional regulation of p73 and p63: development and cancer. Trends Biochem Sci 28: 663-670.

Mills AA, Zheng B, Wang XJ, Vogel H, Roop DR, Bradley A. 1999. p63 is a p53 homologue required for limb and epidermal morphogenesis. Nature 398: 708-713.

Nakagawa T, Takahashi M, Ozaki T, Watanabe K, Hayashi S, Hosoda M, Todo S, Nakagawara A. 2003. Negative autoregulation of $\mathrm{p} 73$ and $\mathrm{p} 53$ by DeltaNp73 in regulating differentiation and survival of human neuroblastoma cells. Cancer Lett 197: 105-109.

Nakagawa T, Takahashi M, Ozaki T, Watanabe Ki K, Todo S, Mizuguchi H, Hayakawa T, Nakagawara A. 2002. Autoinhibitory regulation of $\mathrm{p} 73$ by $\delta \mathrm{Np} 73$ to modulate cell survival and death through a p73-specific target element within the $\delta \mathrm{Np} 73$ promoter. Mol Cell Biol 22: 2575-2585.

Nicotera P, Melino G. 2005. Neurodevelopment on route p63. Neuron 48: 707-709.

Niikura Y, Dixit A, Scott R, Perkins G, Kitagawa K. 2007. BUB1 mediation of caspase-independent mitotic death determines cell fate. J Cell Biol 178: 283-296.

Nylander K, Vojtesek B, Nenutil R, Lindgren B, Roos G, Zhanxiang W, Sjostrom B, Dahlqvist A, Coates PJ. 2002. Differential expression of p63 isoforms in normal tissues and neoplastic cells. J Pathol 198: 417-427.

Ollmann M, Young LM, Di Como CJ, Karim F, Belvin M, Robertson S, Whittaker K, Demsky M, Fisher WW, Buchman A, et al. 2000. Drosophila p53 is a structural and functional homolog of the tumor suppressor p53. Cell 101: $91-101$

Ou HD, Löhr F, Vogel V, Mäntele W, Dötsch V. 2007. Structural evolution of C-terminal domains in the p53 family. EMBO J 26: 3463-3473.

Pozniak CD, Radinovic S, Yang A, McKeon F, Kaplan DR, Miller FD. 2000. An anti-apoptotic role for the p53 family member, p73, during developmental neuron death. Science 289: 304-306.

Pozniak CD, Barnabé-Heider F, Rymar VV, Lee AF, Sadikot AF, Miller FD. 2002. p73 is required for survival and maintenance of CNS neurons. J Neurosci 22: 9800-9809.

Pozzi S, Zambelli F, Merico D, Pavesi G, Robert A, Maltère P, Gidrol X, Mantovani R, Vigano MA. 2009. Transcriptional network of p63 in human keratinocytes. PLoS One 4: e5008.

Puig P, Capodieci P, Drobnjak M, Verbel D, Prives C, Cordon-Cardo C, Di Como CJ. 2003. p73 Expression in human normal and tumor tissues: Loss of $p 73 \alpha$ expression is associated with tumor progression in bladder cancer. Clin Cancer Res 9: 5642-5651.

Rinne T, Brunner HG, van Bokhoven H. 2007. p63-associated disorders. Cell Cycle 6: 262-268.

Rinne T, Bolat E, Meijer R, Scheffer H, van Bokhoven H. 2009. Spectrum of p63 mutations in a selected patient cohort affected with ankyloblepharon-ectodermal defects-cleft lip/palate syndrome (AEC). Am J Med Genet A 149A: 1948-1951.

Rinne T, Hamel B, van Bokhoven H, Brunner HG. 2006. Pattern of $\mathrm{p} 63$ mutations and their phenotypes-update. $\mathrm{Am} J$ Med Genet 140: 1396-1406.

Rocco JW, Leong CO, Kuperwasser N, DeYoung MP, Ellisen LW. 2006. p63 mediates survival in squamous cell carcinoma by suppression of p73-dependent apoptosis. Cancer Cell 9: 45-56.

Schumacher B, Hofmann K, Boulton S, Gartner A. 2001. The C. elegans homolog of the p53 tumor suppressor is required for DNA damage-induced apoptosis. Curr Biol 11: $1722-1727$.

Schumacher B, Schertel C, Wittenburg N, Tuck S, Mitani S, Gartner A, Conradt B, Shaham S. 2005. C. elegans ced-13 can promote apoptosis and is induced in response to DNA damage. Cell Death Differ 12: 153-161.

Senoo M, Pinto F, Crum CP, McKeon F. 2007. p63 Is essential for the proliferative potential of stem cells in stratified epithelia. Cell 129: 523-536.

Serber Z, Lai HC, Yang A, Ou HD, Sigal MS, Kelly AE, Darimont BD, Duijf PHG, van Bokhoven H, McKeon F, et al. 2002. AC-terminal inhibitory domain controls the activity of p63 by an intramolecular mechanism. Mol Cell Biol 22: 8601-8611.

Shimada A, Kato S, Enjo K, Osada M, Ikawa Y, Kohno K, Obinata M, Kanamaru R, Ikawa S, Ishioka C. 1999. The transcriptional activities of p53 and its homologue p51/p63: similarities and differences. Cancer Res 59: 2781-2786.

Stiewe T, Theseling CC, Pützer BM. 2002. Transactivationdeficient $\delta$ TA-p73 inhibits $\mathrm{p} 53$ by direct competition for DNA binding: Implications for tumorigenesis. J Biol Chem 277: 14177-14185.

Straub WE, Weber TA, Schäfer B, Candi E, Durst F, Ou HD, Rajalingam K, Melino G, Dötsch V. 2009. The Cterminus of p63 contains multiple regulatory elements with different functions. Cell Death \& Disease, in press.

Suh EK, Yang A, Kettenbach A, Bamberger C, Michaelis AH, Zhu Z, Elvin JA, Bronson RT, Crum CP, McKeon F. 2006. p63 protects the female germ line during meiotic arrest. Nature 444: 624-628. 


\section{Dötsch et al.}

Tomasini R, Tsuchihara K, Tsuda C, Lau SK, Wilhelm M, Rufini A, Tsao MS, Iovanna JL, Jurisicova A, Melino G, et al. 2009. TAp73 regulates the spindle assembly checkpoint by modulating BubR1 activity. Proc Natl Acad Sci 106: $797-802$.

Tomasini R, Tsuchihara K, Wilhelm M, Fujitani M, Rufini A, Cheung CC, Khan F, Itie-Youten A, Wakeham A, Tsao MS, et al. 2008. TAp73 knockout shows genomic instability with infertility and tumor suppressor functions. Genes Dev 22: 2677-2691.

Truong AB, Kretz M, Ridky TW, Kimmel R, Khavari PA. 2006. p63 regulates proliferation and differentiation of developmentally mature keratinocytes. Genes Dev 20: 3185-3197.

Urist MJ, Di Como CJ, Lu ML, Charytonowicz E, Verbel D, Crum CP, Ince TA, McKeon FD, Cordon-Cardo C. 2002. Loss of $\mathrm{p} 63$ expression is associated with tumor progression in bladder cancer. Am J Pathol 161: 1199-1106.

van Bokhoven H, Brunner HG. 2002. Splitting p63. Am J Hum Genet 71: 1-13.

Vikhanskaya F, Toh WH, Dulloo I, Wu Q, Boominathan L, $\mathrm{Ng} \mathrm{HH}$, Vousden KH, Sabapathy K. 2007. p73 supports cellular growth through c-Jun-dependent AP-1 transactivation. Nat Cell Biol 9: 698-705.
Walsh GS, Orike N, Kaplan DR, Miller FD. 2004. The invulnerability of adult neurons: A critical role for p73. J Neurosci 24: 9638-9647.

Yamaguchi K, Wu L, Caballero OL, Hibi K, Trink B, Resto V, Cairns P, Okami K, Koch WM, Sidransky D, et al. 2000. Frequent gain of the $\mathrm{p} 40 / \mathrm{p} 51 / \mathrm{p} 63$ gene locus in primary head and neck squamous cell carcinoma. Int J Cancer 86: 684-689.

Yang A, Kaghad M, Wang Y, Gillett E, Fleming MD, Dotsch V, Andrews NC, Caput D, McKeon F. 1998. p63, a p53 homolog at 3q27-29, encodes multiple products with transactivating, death-inducing, and dominant-negative activities. Mol Cell 2: 305-316.

Yang A, Schweitzer R, Sun D, Kaghad M, Walker N, Bronson RT, Tabin C, Sharpe A, Caput D, Crum C, et al. 1999. P63 is essential for regenerative proliferation in limb, craniofacial and epithelial development. Nature 398: 714-718.

Yang A, Walker N, Bronson R, Kaghad M, Oosterwegel M, Bonnin J, Vagner C, Bonnet H, Dikkes P, Sharpe A, et al. 2000. P73-deficient mice have neurological, pheromonal and inflammatory defects but lack spontaneous tumours. Nature 404: 99-103.

Zhu J, Jiang J, Zhou W, Chen X. 1998. The potential tumor suppressor p 73 differentially regulates cellular p53 target genes. Cancer Res 58: 5061-5065. 


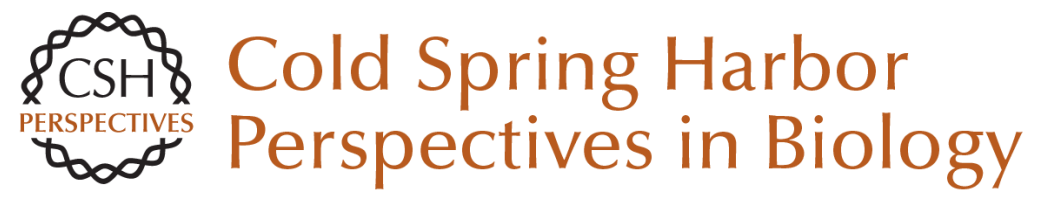

\title{
p63 and p73, the Ancestors of p53
}

\author{
V. Dötsch, F. Bernassola, D. Coutandin, E. Candi and G. Melino
}

Cold Spring Harb Perspect Biol 2010; doi: 10.1101/cshperspect.a004887 originally published online May 19,2010

\section{Subject Collection The p53 Family}

The Origins and Evolution of the p53 Family of Genes

Vladimir A. Belyi, Prashanth Ak, Elke Markert, et al.

Mouse Models of p53 Functions Guillermina Lozano

TP53 Mutations in Human Cancers: Origins, Consequences, and Clinical Use

Magali Olivier, Monica Hollstein and Pierre Hainaut

p53 Research: The Past Thirty Years and the Next Thirty Years

David Lane and Arnold Levine

Transcriptional Regulation by P53

Rachel Beckerman and Carol Prives

p53-based Cancer Therapy

David P. Lane, Chit Fang Cheok and Sonia Lain

Phylogeny and Function of the Invertebrate p53

Superfamily

Rachael Rutkowski, Kay Hofmann and Anton Gartner

Tied Up in Loops: Positive and Negative

Autoregulation of p53

Xin Lu
The Tumor Suppressor p53: From Structures to

Drug Discovery

Andreas C. Joerger and Alan R. Fersht

p53 Regulation of Metabolic Pathways

Eyal Gottlieb and Karen H. Vousden

The Regulation of the p53-mediated Stress

Response by MDM2 and MDM4 Mary Ellen Perry

Zebrafish Models of p53 Functions Narie Y. Storer and Leonard I. Zon

$p 63$ and p73, the Ancestors of p53

V. Dötsch, F. Bernassola, D. Coutandin, et al.

Pathologies Associated with the p53 Response Andrei V. Gudkov and Elena A. Komarova

Single-nucleotide Polymorphisms in the p53

Signaling Pathway

Lukasz F. Grochola, Jorge Zeron-Medina, Sophie Mériaux, et al.

Clinical Outcomes and Correlates of TP53

Mutations and Cancer

Ana I. Robles and Curtis C. Harris

For additional articles in this collection, see http://cshperspectives.cshlp.org/cgi/collection/

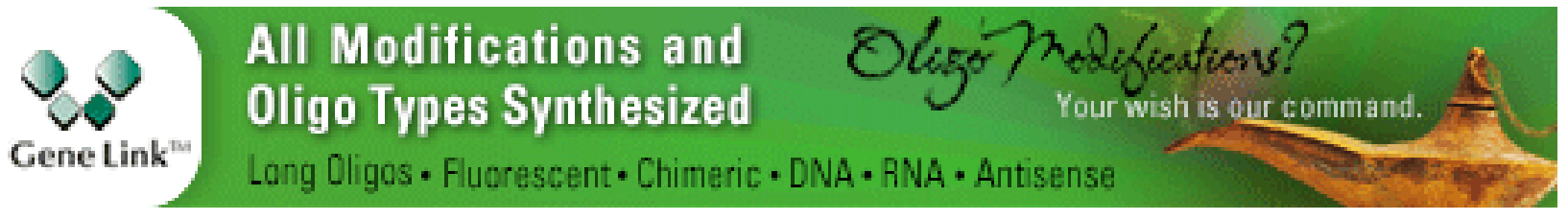

Copyright @ 2010 Cold Spring Harbor Laboratory Press; all rights reserved 